\title{
A importância do marketing relacional na gestão do restaurante Sete Portes
}

\author{
The importance of relationship marketing in the management of Sete Portes \\ restaurant
}

\author{
Ana Márcia Parente \\ Instituto Politécnico de Viana do Castelo, Portugal \\ marcia_parente_2@hotmail.com \\ Pedro Miguel Carvalho \\ Instituto Politécnico de Viana do Castelo, CITUR, Portugal \\ pc@estg.ipvc.pt
}

\begin{abstract}
Resumo
Este artigo tem como objetivo contribuir para uma melhor compreensão da importância do marketing relacional na gestão de um restaurante. Para o efeito, desenvolve-se um estudo de caso de um conceituado restaurante localizado na cidade de Barcelona - o restaurante Sete Portes. Recorrendo ao Modelo dos seis mercados de Christopher, Payne e Ballantyne (2002), ilustra-se o modelo de gestão de relações deste restaurante e demonstra-se a sua relevância no processo de criação valor para os diferentes stakeholders. Este estudo de caso poderá ser uma ferramenta útil no processo de ensino do marketing relacional em cursos de licenciatura e mestrado.
\end{abstract}

Palavras-chave: Marketing relacional; CRM; Modelo dos seis mercados; restaurante; Barcelona.

\begin{abstract}
This article aims to contribute to a better understanding of the importance of relationship marketing in the management of a restaurant. To this end, a case study of a renowned restaurant located in the city of Barcelona was developed - the Sete Portes restaurant. Using the Six Markets Model of Christopher, Payne and Ballantyne (2002), the relationship management model of this restaurant is illustrated and its relevance in the process of creating value for the different stakeholders is shown. The case study developed may be a useful tool in the process of teaching relationship marketing in undergraduate and masters' degrees.
\end{abstract}

Keywords: Relationship marketing; CRM; six markets model; restaurant; Barcelona.

\section{Introdução}

De acordo com a World Travel \& Tourism Council (WTTC), o turismo é uma das indústrias mais significativas na economia dos países, representando, atualmente, cerca de 11\% do PIB Mundial. Em 2015, tendo em conta as contribuições diretas e indiretas, o turismo representou para o PIB 6,6 triliões de dólares a nível mundial e empregou diretamente mais de 100 milhões de pessoas. Ao longo da próxima década, espera-se que o setor do turismo forneça um total de 74,5 milhões de novos postos de trabalho, 23,2 milhões dos quais serão fornecidos diretamente

Dos Algarves: A Multidisciplinary e-Journal, 34-2019.

ISBN 2182-5580 ๑ ESGHT - University of the Algarve, Portugal.

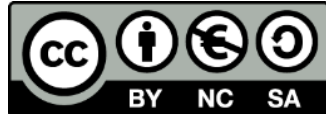


dentro do sector (WTTC, 2016). ${ }^{1}$ Os dados da WTTC mostram que a atividade do turismo tem crescido exponencialmente a partir da década de 50, representando um crescimento originário do fenómeno económico, cultural e social da recuperação do pós-guerra. O turismo assume-se assim como uma indústria fortemente ativa na economia mundial, sendo responsável por gerar empregabilidade e intercâmbio de conhecimentos.

Curiosamente, a gastronomia começa também a ganhar relevância no processo de decisão do turista face a toda a oferta, conquistando um segmento específico de mercado. Segundo Tresserras e Medina (2007: 218), as qualidades ligadas à gastronomia distinguem-se como "um fator decisivo na planificação da viagem". Isto significa, que a experiência da gastronomia local é transformada num produto de consumo. Com efeito, a gastronomia poderá ser encarada como um recurso que se pode rentabilizar através do turismo pelo seu consumo em estabelecimentos de restauração (Contreras, 2007).

Neste contexto, o marketing relacional desempenha um papel essencial na capacidade de uma empresa, nomeadamente de um restaurante, manter e desenvolver relações duradouras com os seus clientes (Antunes \& Rita, 2008; Brito, 2011a; Šonková \& Grabowska, 2015; Ryu \& Lee, 2017; Hyun \& Perdue, 2017). Todavia, conforme refere Carvalho (2004), só é possível fortalecer os relacionamentos com o cliente através de uma boa gestão de relações com os diferentes stakeholders. Assim, este artigo visa compreender como um restaurante, a partir dos relacionamentos que estabelece, cria valor para os diferentes grupos de interesse.

De modo a concretizar o objetivo deste artigo, é desenvolvido um estudo empírico centrado num estudo de caso de um restaurante bastante conceituado em Barcelona - o restaurante Sete Portes. Ora, para compreender a dinâmica das suas relações e a forma como contribuem no processo de criação de valor para os diferentes stakeholders, recorreu-se ao Modelo dos seis mercados do marketing relacional proposto por Christopher et al., 2002).

Sem descurar a relevância das implicações para a gestão do restaurante Sete Portes decorrentes do diagnóstico desenvolvido, almeja-se que este estudo de caso possa ser uma ferramenta útil no processo de ensino do marketing relacional em cursos de licenciatura e mestrado.

Este artigo apresenta, assim, a seguinte estrutura: a próxima secção apresenta uma revisão teórica de literatura, a subsequente secção expõe a metodologia empreendida, na terceira secção é apresentado um estudo de caso de uma unidade de restauração e, na secção final, são apresentadas as conclusões e implicações do estudo desenvolvido.

\section{Revisão da literatura}

Os relacionamentos em marketing desenvolveram-se de uma forma muito especial, a partir da década de 90, com o desenvolvimento das tecnologias de comunicação e informação, nomeadamente da internet. Nesse período, o paradigma de marketing transfigurou-se, passando de um foco de mercado de vendas e de produtos de grande consumo para uma abordagem relacional com o cliente. As relações transacionais foram impulsionadas com novos canais de comunicação mais eficientes, bem como através da nova abordagem herdada do marketing industrial, designadamente da Escola Nórdica (Grupo IMP) e do marketing de

\footnotetext{
${ }^{1}$ Disponível em https:/pt.slideshare.net/jimmytomkat/world2016, acedido em 27 de junho de 2016.
} 
serviços, que tem/têm reorientado a forma da empresa se relacionar com os clientes (Brito, 2011b).

Isto significa que o marketing relacional tem na sua génese diferentes escolas de pensamento. Todavia, deve-se à Escola Anglo-Australiana, nomeadamente a Martin Christopher, Adrian Payne e David Ballantyne entre outros contributos, um trabalho relevante no domínio das relações com diferentes grupos de stakeholders, que deu origem ao chamado Modelo dos seis mercados (Brito, 2011a).

Christopher et. al. (2002) apresentaram uma ferramenta, que aborda a gestão de relações com os principais stakeholders de uma empresa, aquilo que os seus autores designaram "mercados", agrupados em seis conjuntos, designadamente: Mercados de clientes, Mercados de fornecedores e alianças, Mercados de recrutamento/treinamento, Mercados de influência e Mercados de referência (Figura 1).

De acordo com Brito, Ramos e Carvalho (2006: 17):

\begin{abstract}
Os seis mercados variam em importância. Como tal, é fundamental compreender as suas dinâmicas e identificar os aspetos críticos que não só influenciam a estratégia da empresa, mas também afetam a sua posição competitiva. A partir dessa análise, as empresas serão capazes de visualizar grupos-chave existentes dentro de cada um desses mercados, e desenvolver estratégias de relacionamento que, em termos de resultado final, possam aumentar o valor gerado para o cliente.
\end{abstract}

Para uma melhor compreensão deste modelo, analisa-se, seguidamente, cada um dos mercados.

Figura 1. Modelo dos seis mercados

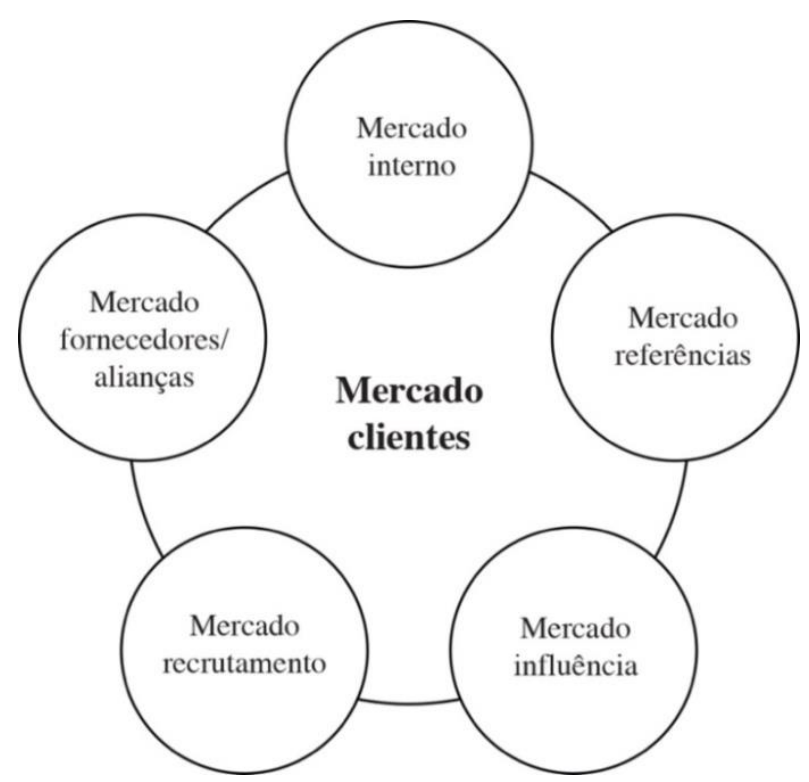

Fonte: Christopher et al. (2002: 80).

\title{
2.1. Mercado de clientes
}

O mercado de clientes é composto por três entidades: os compradores diretos, concretamente, aqueles, que compram diretamente à empresa; os compradores 
intermediários, que se identificam na atividade de revenda, uma vez que compram aos compradores diretos e, em seguida, revendem; e os consumidores finais, que se situam no final da cadeia de valor e que adquirem aos retalhistas (Christopher et al., 2002).

Para Christopher et al. (2002), as empresas devem procurar estabelecer relacionamentos com os seus clientes, tendo em vista maximizar o seu valor, mas avaliando os custos e benefícios resultantes do investimento nessa relação. Ora, o modelo de relacionamento com todos os clientes, não deverá ser rigorosamente igual.

Para que a empresa identifique os clientes a investir numa relação e compreenda como desenvolver essa relação, é desejável que avalie o valor de vida dos seus clientes, uma vez que cada um apresenta um diferente valor para a empresa. Assim, o valor do cliente poderá ser medido em termos reais ou em termos potenciais (Peppers et al., 1993; Brito et al., 2006; Estrella-Ramón, Sánchez-Pérez, Swinnen \& Vanhoof, 2016).²

\subsection{Mercado de fornecedores e alianças}

Para Ford, Gadde, Hakansson, Lundgren, Snehota, Turnbull e Wilson (1998) a empresa poderá ter vários motivos para a escolha de um fornecedor, designadamente pela sua capacidade de introduzir melhorias na performance dos produtos ou serviços (componentes e processos mais adaptados às necessidades do cliente), capacidade de transferir conhecimento ou ainda a habilidade para reduzir custos de produção, I\&D e administrativos da empresa cliente.

Em sintonia com estes investigadores, estão Christopher et al. (2002), manifestando que a escolha do parceiro certo é vital para o bom funcionamento de qualquer empresa. Isto significa que, apesar dos fornecedores e alianças deverem ser encarados como parceiros, existe uma distinção entre cada um dos intervenientes, assim: (i) o Mercado de fornecedores é constituído por empresas, que têm a função na cadeia de valor de fornecer os recursos físicos ou serviços às empresas na cadeia de valor, para que o produto final se concretize. $O$ aprovisionamento de bens palpáveis pode ser acompanhado com serviços complementares; (ii) o Mercado de alianças, que são consideradas parcerias, envolve a união de várias empresas para se concretizar um determinado produto ou serviço. Este fortalecimento de competências está associado à subcontratação entre diferentes entidades que podem complementar-se no fornecimento de componentes de produtos ou serviços especializados.

\subsection{Mercado de referências}

De acordo com Christopher et al. (2002), a referenciação "passa-palavra", como meio de comunicação, permite a divulgação da imagem de uma determinada empresa e é importante como uma forma de captação de potenciais clientes. Para estes investigadores, este "passapalavra" resulta de duas categorias no mercado de referências: referências de clientes (advocates e customer-based development) e de referências de não clientes (general referrals, reciprocal referrals, incentive-based referrals e staff referrals).

\footnotetext{
${ }^{2}$ De acordo com o Brito et al. (2006: 45), o life-time value (LTV) ou o valor de vida do cliente consiste no "valor de um cliente medido em função dos lucros que ele gera ao longo do seu relacionamento com a empresa". O valor potencial do cliente poderá ser avaliado, com base nas análises do histórico da relação com o cliente e em previsões futuras da sua evolução (Brito et al., 2006; Peppers \& Rogers, 1993).
} 
De acordo com estes autores, a importância de cada categoria vai depender do tipo de organização, setor, tipo de produto ou serviço prestado. Com efeito, Christopher et al. (2002) salientam que as empresas devem constatar qual a tipologia que mais se identifica na sua organização e posteriormente recompensar as referências mais relevantes.

\subsection{Mercado de influências}

O Mercado de influências é composto por grupos de atores com capacidade de exercer influência em diversos níveis da organização de uma empresa, por meio de decisões ou opiniões. Este grupo pode ser constituído por entidades ligadas à área financeira, governo, usuários, agências de cotação de crédito, imprensa empresarial e organizações ambientalistas (Christopher et al., 2002). Segundo estes investigadores, a correta gestão dos vários grupos influenciadores (ex. mercado financeiro e de investimento, mercado de influência de organizações ambientalistas, mercado de influência de concorrência e mercado de influência política e entidades reguladoras), passa por traçar uma estratégia de marketing apropriada. No momento atual, o investimento em políticas ligadas a estratégias de sustentabilidade, indica um forte grupo de influência ativo nesta temática, pelo que é necessário redobrar a atenção em estratégias vocacionadas para a responsabilidade social (Doh, Howton, Howton \& Siegel, 2010).

\subsection{Mercado de recrutamento}

Num mercado cada vez mais competitivo, as empresas já perceberam que o capital humano é mais importante que o capital financeiro. Equipas treinadas e com experiência, são consideradas elementos vitais de uma empresa por acrescentarem valor aos produtos/serviços. Para Christopher et al. (2002) são as pessoas que fazem uma empresa funcionar "mecanicamente" na sua organização e são a "cara" na comunicação com o cliente. Por isso, numa situação ideal de recrutamento, os gestores de recursos humanos devem considerar o perfil de candidato mais adequado à sua empresa e definir critérios para que o processo de recrutamento seja eficaz, que passam pelas seguintes ações: (i) Criação de um clima organizacional apropriado; (ii) Comunicação dos benefícios da empresa a potenciais colaboradores; (iii) Definição do perfil de colaborador a ser recrutado que satisfaça a imagem que a empresa pretende que venha a ser projetada.

\subsection{Mercado interno}

Do mesmo modo que o marketing externo investe nos clientes externos, o marketing interno "encara" os colaboradores da organização como se fossem clientes, reconhecendo que a satisfação dos clientes externos é condicionada pela satisfação dos clientes internos (Aburoub, Hersh \& Aladwan, 2011; Marques, 2012; Choi \& Joung, 2017; Balta, 2018). Assim, Christopher et al. (2002: 112) admitem que:

O mercado interno envolve reconhecer a importância de atrair, motivar, treinar e manter colaboradores de qualidade através do desenvolvimento de empregos que consigam satisfazer as necessidades individuais. O marketing interno visa incentivar os trabalhadores a se comportarem de forma a atrair clientes para a empresa. Além disso, as pessoas mais talentosas vão querer trabalhar nas empresas que valorizam os seus funcionários. 
De acordo com estes autores, a empresa deve-se empenhar, tendo em vista garantir que todos os colaboradores recebem qualidade de serviço da empresa e, de igual modo, prestem qualidade de serviço aos clientes externos. Mais ainda, é fundamental um envolvimento dos colaboradores nos objetivos, missão e estratégia definidos.

Ora, tendo por base o Modelo dos seis mercados, apresentado por Christopher et al., (2002), este artigo tem como objetivo compreender como o valor criado para o turista é incrementado pelos relacionamentos desenvolvidos pelas entidades que produzem uma atração turística. De modo mais específico, procura-se compreender como um restaurante localizado em Barcelona (restaurante Sete Portes) gere os relacionamentos com os diferentes stakeholders, de forma a criar valor para os seus clientes.

\section{Metodologia}

De modo a concretizar o objetivo deste trabalho, é desenvolvido um estudo empírico centrado num estudo de caso de um restaurante bastante conceituado na cidade de Barcelona. Para efeitos de recolha de dados, recorreram-se a fontes de pesquisa de dados primários e secundários, como iremos analisar seguidamente.

\subsection{Método de pesquisa}

Embora, tradicionalmente, o estudo de caso não fosse entendido como uma estratégia formal de pesquisa, mas como um estágio exploratório de menor importância, atualmente, é utilizado em diversas áreas científicas, tais como, a sociologia, psicologia, estudos organizacionais e ciências sociais (Yin, 1994). De acordo com Yin (2001), o estudo de caso valoriza a atuação perante a realidade contextualizada, de forma a adquirir conhecimento do fenómeno estudado. Todavia, o investigador "enfrenta uma situação tecnicamente única em que haverá muito mais variáveis de interesse do que pontos de dados e, baseia-se em várias fontes de evidências, com os dados a precisar de convergir para um formato de triângulo e, beneficia-se do desenvolvimento prévio de proposições teóricas para conduzir a recolha e análise de dados." (Yin, 2001: 33). Ora, a metodologia de estudo de caso é viável para obter dados implícitos e explícitos de determinado assunto. Por isso, este método está vinculado a múltiplas fontes de recolha de dados, tais como, recolha de documentos, observação direta e entrevistas, com o intuito de não crer unicamente numa única fonte de dados (Yin, 2001).

\subsection{Recolha e análise de dados}

A pesquisa primária teve lugar na cidade de Barcelona, mais concretamente, nas organizações onde foram realizadas entrevistas, tais como: Fundació Institut Catalá de la Cuina i de la Cultura Gastronómica (FICCG), restaurante Sete Portes e Turismo da Catalunha. As entrevistas foram realizadas entre os meses de março e junho de 2015. Durante esse período, foram realizadas duas entrevistas em profundidade, designadamente à diretora geral da FICCG e à diretora do restaurante Sete Portes, com cerca de uma hora e meia de gravação áudio (cada uma), seguindo um guião semiestruturado, em consonância com a revisão de literatura. Nessa fase, também foi inquirido por e-mail, o responsável pelo departamento de marketing do Turismo da Catalunha, através de um questionário estruturado. 
Para efeitos de organização de dados, foram transcritas as gravações obtidas e, a sua interpretação, partiu de proposições teóricas resultantes da revisão de literatura combinadas com as aptidões e experiência dos investigadores. Os dados foram validados pelo método de triangulação. Com efeito, suplementarmente foram recolhidos relatórios pedidos por via oficiosa, folhetos publicitários e artigos disponíveis na internet associados às organizações referidas. Esta abordagem de validação está vinculada a múltiplas fontes de recolha de dados, que permitiram corroborar a informação, com várias fontes de evidências.

\subsection{Uma aplicação pedagógica}

O estudo de caso, enquanto técnica pedagógica, permite uma aproximação à dimensão real, promovendo nos alunos competências para tomar decisões, com base no contributo dos alunos com diferentes experiências, saberes e pontos de vista (Easton, 1992; Blunden \& McGuinness, 1993; Corey, 1996). Deste modo, é de afirmar que, o estudo de caso restaurante Sete Portes poderá ser uma ferramenta importante no processo de aprendizagem em cursos de licenciatura e mestrado, contribuindo para a compreensão dos principais fatores a analisar num diagnóstico aos relacionamentos de uma dada empresa, tendo em vista o desenvolvimento de uma eficiente estratégia de marketing. Por outro lado, este estudo permite evidenciar, em contexto de aula, que a atividade de marketing centrada somente no cliente começa a cair em desuso, uma vez que descura e não explora o potencial que a empresa pode vir a ter se os seus vários stakeholders forem considerados. Por último, este caso permite ainda mostrar aos alunos que, o Modelo dos seis mercados, visa contribuir para uma gestão mais eficiente dos fornecedores, concorrentes, colaboradores, instituições influenciadoras e, em última instância, para o aumento da satisfação e fidelização dos clientes.

\section{4. $O$ estudo de caso: Restaurante Sete Portes}

O edifício em que se localiza o restaurante Sete Portes tem uma dimensão história e expressiva na cidade de Barcelona. O empresário Josep Xifre y Casas, durante o século XIX, investiu no Passeig de Isabel II e contruiu um edifício em arcada, voltado para a rua e inspirado nas casas de praça em Paris. ${ }^{3}$

As ideias inovadoras do empresário materializaram-se e surgiu assim um equipamento capaz de albergar uma série de escritórios, um café extravagante e a sua própria residência. A arcaria do edifício era constituída por oito portas em que, uma delas, era vocacionada para o serviço dos funcionários do estabelecimento e, as restantes sete, constituíam a entrada do atual restaurante Sete Portes. A contextualização histórica do local foi propícia à criação de um dos restaurantes mais populares e antigos da cidade, contando hoje com 170 anos de idade (Figuras 2 e 3).

\footnotetext{
3 Disponível em https://7portes.com/es/restaurante-emblematico-barcelona/, acedido em 27 de novembro de 2015.
} 


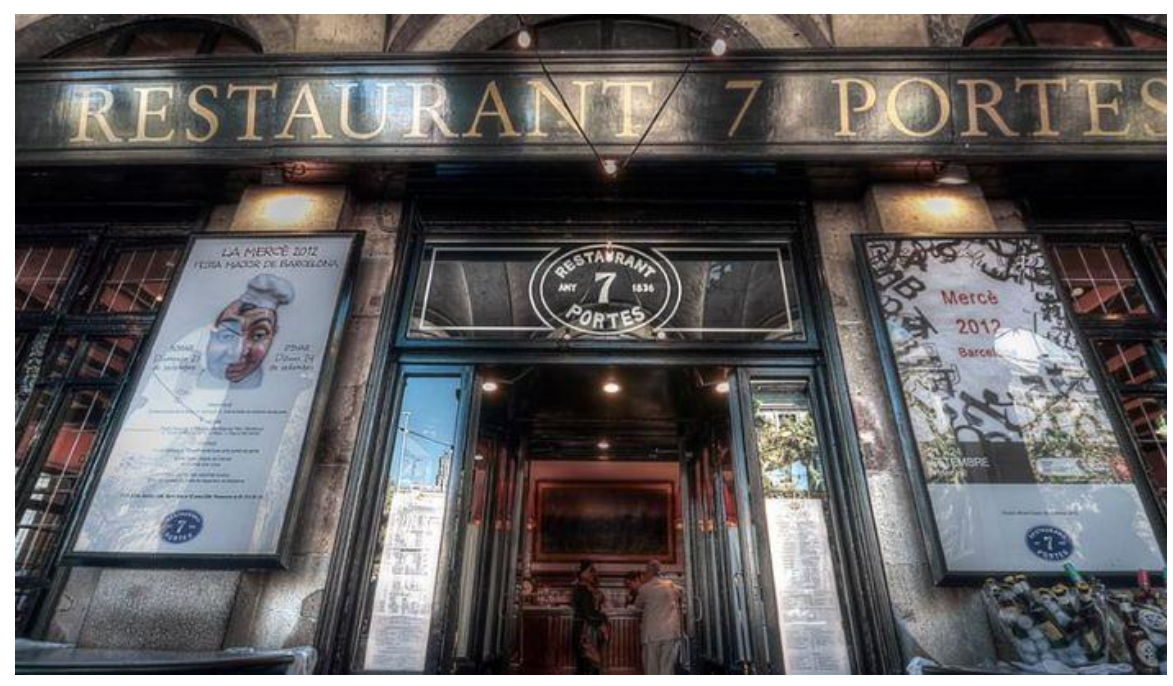

Fonte: TripAdvisor - Restaurante Sete Portes.

A disposição original dos diferentes salões e quartos que formam o edifício é mantida. A valorização histórica, aliada à qualidade de serviço e gosto culinário da região, constiuem a fórmula da excelência reconhecida por qualquer cliente da cidade e pelos turistas que a visitam.

Figura 3. Sala do restaurante Sete Portes

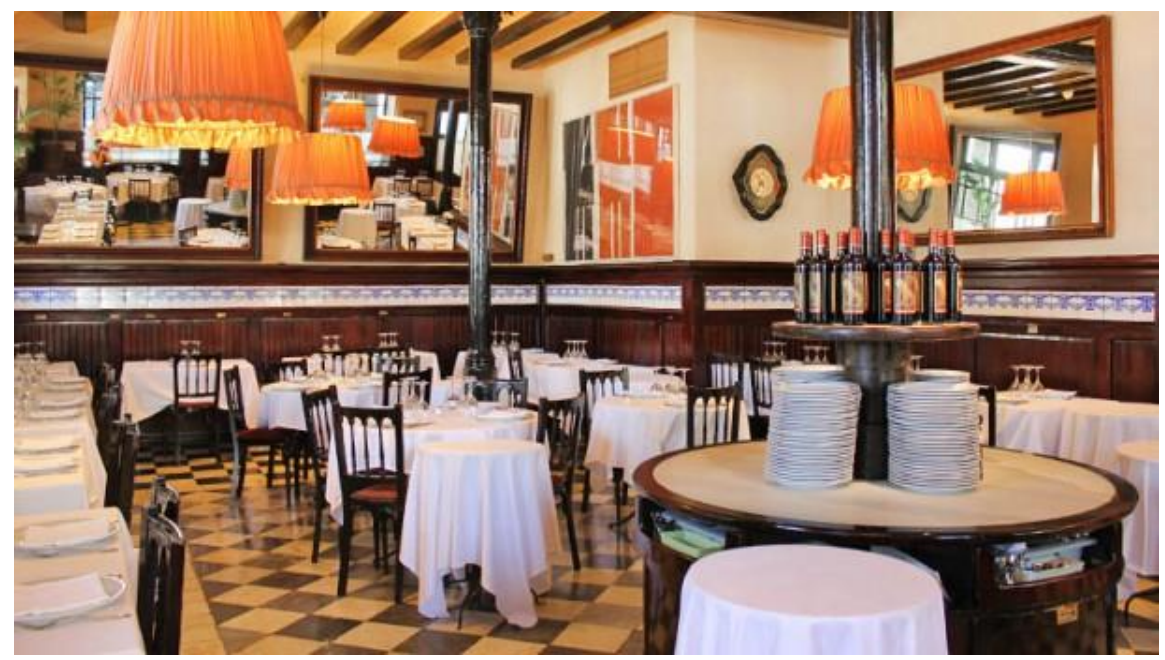

Fonte: TripAdvisor - Restaurante Sete Portes.

Determinação, confiança, empenho, são alguns dos elementos fundamentais para trabalhar no restaurante Sete Portes. Cristina Biosca, diretora geral do restaurante Sete Portes, afirma que um restaurante é uma empresa de serviços e que o capital humano é fundamental para poder funcionar bem. 


\subsection{A gestão de relações com clientes}

O restaurante Sete Portes, não tem uma estratégia de marketing formal, mas tem uma equipa de gestão e colaboradores de sala, que trabalham afincadamente para que os clientes se sintam satisfeitos.

Estabelecendo relacionamentos com os clientes, face a face, na web, por telefone e viaemail, o Sete Portes procura retirar o máximo desta interação, adotando estratégias de marketing que contribuem para manter os seus atuais clientes, como também para garantir a conquista de novos.

O restaurante Sete Portes tem um atendimento de excelência, tratando os seus clientes afavelmente, sejam estes habituais ou novos. Os clientes habituais são extremamente importantes para o Sete Portes, uma vez que, são clientes fidelizados e que podem atrair novos, na medida em que recomendam o restaurante a potenciais clientes.

Neste sentido, destacam-se um conjunto de políticas que têm vindo a ser desenvolvidas e que criam valor para o cliente, ajudando assim na sua retenção e na conquista de novos clientes:

- Visitam cerca de 200 mil pessoas ao ano o restaurante Sete Portes e, uma das formas de controlar a qualidade de serviço proporcionada, é recorrer à administração de questionários junto dos clientes (interrogando-os sobre a qualidade da comida, decoração e atendimento), com o objetivo de serem tomadas ações corretivas e melhorar o serviço prestado;

- O website do Sete Portes é de fácil navegação, dispõe de informação em catalão, espanhol e inglês sobre a história do restaurante, localização e menus. Permite também realizar uma visita virtual ao restaurante, comprar livros de receituário e realizar reservas por e-mail ou telefone. A informação é altamente detalhada, o que se torna um fator fortemente estimulador do processo de escolha por parte dos clientes mais exigentes e contribui para uma maior interatividade entre o cliente e o restaurante.

- Todos os menus têm um selo de certificação nas suas cartas e existe uma placa à entrada do restaurante que exibe a marca Cuina Catalana. ${ }^{4}$ Ora, os clientes que têm conhecimento da existência desta marca, privilegiam, naturalmente, um restaurante certificado. Embora seja de destacar que um número significativo de clientes ainda não conhece a referida marca.

Importa salientar também, que a monitorização, sob a forma de inquérito, relativamente à gestão operacional e funcionamento do restaurante, permite à equipa de gestão fazer ajustes na sua proposta de valor, atendendo à tipologia de clientes que visitam o restaurante Sete Portes, nas diferentes épocas do ano.

Relativamente à fidelização de clientes, não existe uma política concreta de procedimentos deste restaurante para a retenção de clientes.

\footnotetext{
${ }^{4}$ A marca Cuina Catalana foi criada pela Fundació Institut Catalá de la Cuina i de la Cultura Gastronomica, sendo única no intuito de certificar, preservar e divulgar os produtos alimentares produzidos na Catalunha, estabelecimentos comerciais e a cozinha tradicional (Fundació Institut Catalá de la Cuina, 2014).
} 


\subsection{Gestão de relações de influenciadores}

O mercado de influenciadores do restaurante Sete Portes é constituído por diversos grupos, nomeadamente pelos órgãos de comunicação social, defesa do consumidor, sindicatos, universidades, FICCG/MCC, Turismo de Barcelona, Turismo da Catalunha, Generalitat da Catalunha (Governo da Comunidade Autónoma da Catalunha) e empresas de animação (Figura 4).

O trabalho realizado em conjunto por estes organismos é importante, uma vez que a vinda de mais turistas à cidade de Barcelona influencia diretamente as receitas que o restaurante obtém. Por este motivo, o êxito do turismo de Barcelona não é solitário e não se deve exclusivamente a uma instituição. Deste modo, resulta de um trabalho conjunto, de colaboração direta e indireta de várias instituições e empresas que se entreajudam.

O restaurante Sete Portes coopera ou tenta cooperar com todos os organismos públicos ou privados. Neste sentido, colaboram com a FICCG, Turismo de Barcelona e Turismo da Catalunha, em pedidos de informações necessárias, para o bom funcionamento do restaurante. Também tem parcerias com hotéis e empresas como a e-Project, ${ }^{5}$ para quando realizam concertos, noites temáticas ou alguma atividade de animação diferente.

Figura 4. Grupos influenciadores do restaurante Sete Portes

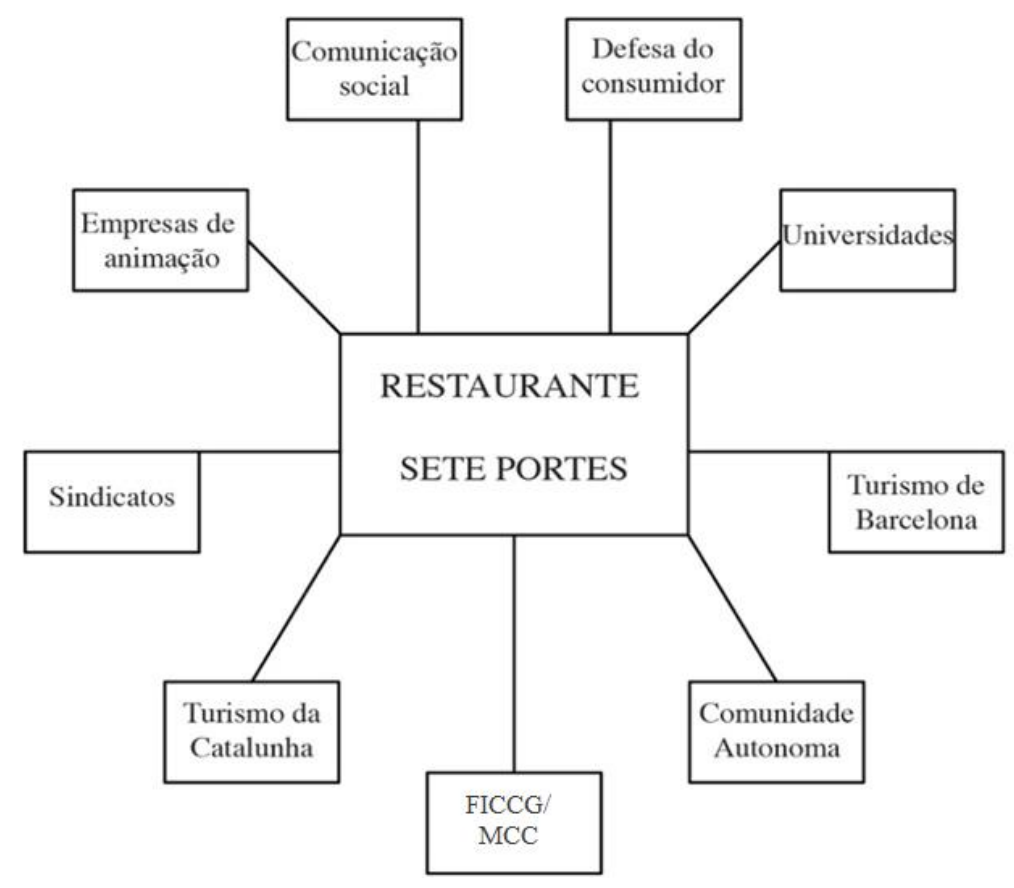

Os restaurantes certificados com a marca Cuina Catalana podem também solicitar informações ou aconselhamento à Generalitat ou ao Turismo de Barcelona. Por outro lado, é de referir que, a nível económico não existe grande apoio, devido à crise económica que afetou

\footnotetext{
${ }^{5}$ A e-Project é uma empresa que realiza concertos, festivais de música, festivais de jazz e jornadas de música.
} 
o orçamento de Estado. Mais é de salientar que, o Turismo de Barcelona, em parceria com restaurantes e hotéis da Catalunha, promove viagens de jornalistas especializados em turismo/gastronomia e concede a oportunidade de referenciar os restaurantes no seu website. Mais ainda, esta organização, quando está presente em feiras internacionais, inclui os restaurantes na sua mostra.

Apesar de já se identificarem algumas parcerias estabelecidas, ainda faz falta uma organização que impulsione mais movimentos, encontros e palestras entre restaurantes, hotéis e empresas que trabalhem no setor do turismo e com a cozinha catalã. Este tipo de iniciativa poderá estreitar as relações entre restaurantes e promover a sua cooperação.

\subsection{Gestão de relações de outros stakeholders}

O restaurante Sete Portes possui clientes que realizam um esforço pró-ativo no sentido de transmitirem uma imagem positiva, por se terem tornado clientes totalmente satisfeitos com os produtos e serviços prestados. No entanto, esta empresa não tem em consideração, nem recompensa os clientes que têm uma atitude positiva e ativa no sentido de influenciar potenciais clientes.

No Sete Portes é fundamental que, os propósitos da empresa estejam bem definidos e clarificados, de forma a viabilizar a integração, motivação e mobilização dos colaboradores. Uma das formas que o restaurante utiliza para motivar os colaboradores, consiste no sistema de incentivos monetários. Estes incentivos são objetivados como realistas, no sentido em que são definidos para se poderem alcançar. De acordo com a diretora geral, os incentivos são importantes, mas devem estar associados a objetivos a atingir e passíveis de cumprir, quer seja pelo encarregado, chefe de cozinha ou funcionários de mesa. Neste sentido, existe consciência que colaboradores que trabalhem motivados passam uma imagem de competência, responsabilidade, iniciativa e profissionalismo. No caso do restaurante Sete Portas, existe um controlo sobre o desempenho dos funcionários. Estes devem ser cumpridores, dedicados e prestar um bom serviço aos clientes. Importa ainda salientar que é concedida formação contínua internamente aos colaboradores durante as horas de trabalho (embora não exista um programa de formação formalmente estruturado), para que estes desempenhem um trabalho exemplar.

O restaurante Sete Portes procura colaboradores formados na área de turismo e restauração, preferencialmente. Por outro lado, recruta pessoas que se enquadrem na imagem e nos objetivos da empresa, que sejam capazes de trabalhar rotativamente e que prestem um bom atendimento ao público. Como esta organização é prestadora de serviços, concede particular relevância a funcionários capazes de lidar com diferentes pessoas e personalidades, assim como com elevado controlo emocional e capacidade para suportar um esforço físico bastante intenso.

Para o restaurante Sete Portes manter o mais alto nível de qualidade e excelência, recorre a produtores locais. Muitos destes produtores trabalham em parceria com a FICCG ou já são conhecidos do restaurante há vários anos.

Relativamente aos principais fornecedores do Sete Portes, encontram-se empresas que laboram em território Catalão, mais especificamente na cidade de Barcelona, uma vez que apresentam vantagens competitivas, pois oferecem um custo de transporte, armazenamento e prazo de entrega das encomendas inferior ao das empresas estrangeiras ou de outras 
regiões de Espanha. No entanto, não existe uma estratégia por parte dos fornecedores do Sete Portes, no sentido de adaptarem os seus processos internos aos processos do restaurante e, deste modo, criarem produtos ou serviços mais customizados. Por isso, não se verifica um esforço de integração dos fornecedores no restaurante, não se procedendo assim a ações de formação e de desenvolvimento dos recursos humanos das empresas fornecedoras. Por outro lado, os colaboradores do Sete Portes não beneficiam de um processo de aprendizagem conduzido pelas empresas que fornecem produtos ou serviços.

No que respeita a alianças entre restaurantes, mesmo os pertencentes à marca, é muito reduzida, devido ao tipo de trabalho que realizam, pelos horários, tensão e pressão a que os restaurantes estão sujeitos. Todavia, existe uma pré-disposição para a colaboração com os restaurantes concorrentes, apesar de que, para a diretora geral, deveria ser a FICCG a estimular mais a relação entre estas organizações.

\section{Conclusões e implicações}

O restaurante Sete Portes aderente à Marca Cuina Catalana é um dos mais relevantes pela sua importância histórica e pelo marco gastronómico que deixou na cidade de Barcelona. Apesar de não constituir um modelo representativo do universo total da indústria da restauração pertencente à Marca Cuina Catalana, foi sugerido pela diretora da FICCG, por permitir expor um caso de sucesso aderente à Marca.

O estudo de caso ilustra o modelo de gestão de relacionamentos do restaurante e demonstra a sua relevância no processo de criação valor para os diferentes stakeholders. Com efeito, este estudo revela como uma organização tem vindo a solidificar o seu posicionamento no mercado ao longo do tempo, a partir da forma como gere a sua rede de relações, nomeadamente com colaboradores, consultores, entidades públicas, entidades privadas, organismos do governo e associações.

Todavia, a partir da análise da dinâmica das relações com os grupos-chave integrados em cada um dos 6 mercados apresentados por Christopher et al. (2002), é possível compreender, que não tem sido de igual modo eficiente a gestão de relacionamentos deste restaurante com os vários stakeholders. Por outro lado, o diagnóstico desenvolvido permite compreender que o modelo de gestão de relacionamentos carece do desenvolvimento de estratégias estruturadas e formais. Por isso, para cada um dos mercados é de realçar:

- Mercado de clientes: Embora não exista uma estratégia formal estabelecida e não seja considerado o valor atual e potencial do cliente, destaca-se um modelo de gestão de relações com clientes que prima pela qualidade no atendimento, assim como pelo controlo sistemático da qualidade de serviço, a partir de questionários realizados numa base regular.

- Mercado de influenciadores: O estudo evidencia o modelo de cooperação existente com organizações como a FICCG, Turismo de Barcelona e Turismo da Catalunha, pela forma como permitem transferir conhecimento e dar visibilidade às unidades de restauração em Barcelona. Todavia, reconhece-se a importância de serem incrementadas relações mais estreitas entre as instituições públicas governamentais e as empresas do sector da hotelaria e restauração. 
- Mercado interno: A direção do restaurante concede muita relevância a funcionários que trabalhem motivados e com sentido de responsabilidade. No entanto, o sistema de incentivos cinge-se a recompensas monetárias e a formação, descurando-se a importância de recompensas imateriais e a integração dos colaboradores nos objetivos e missão da empresa.

- Mercado de fornecedores e alianças: O restaurante Sete Portes é fornecido essencialmente por produtores locais. Contudo, não se verifica um esforço de integração dos fornecedores no restaurante, que permita viabilizar uma adaptação dos seus processos internos aos processos do restaurante e, deste modo, criarem produtos ou serviços mais customizados. No que respeita às alianças estabelecidas com outros restaurantes, é de salientar que, embora exista uma pré-disposição da direção para a colaboração com os restaurantes concorrentes, são exíguas as parcerias existentes.

- Mercado de referências: Apesar de se reconhecer a relevância das referências positivas concedidas pelos clientes, é de destacar que não existe qualquer programa que vise recompensar este grupo-chave.

- Mercado de recrutamento: No processo de recrutamento, é dada importância à qualificação dos funcionários na área da hotelaria e turismo, assim como às suas aptidões relacionais. Todavia, não está definido de forma explícita e formal, em coerência com a imagem que procura transmitir, o perfil de colaboradores que o restaurante deseja recrutar.

Apesar do esforço desenvolvido pelo restaurante, no sentido de gerir relacionamentos de forma eficiente, ainda existe muito trabalho a ser realizado, tendo em vista o aperfeiçoamento das estratégias de relacionamento com os diferentes stakeholders e, por consequência, alavancar o valor proporcionado ao cliente na sua experiência gastronómica. Neste sentido, tendo por base o Modelo dos seis mercados e a título de managerial implications, algumas reflexões são apresentadas, como veremos.

Quando um cliente visita o restaurante pela primeira vez, fá-lo, frequentemente, porque alguém o recomendou. Isto significa, que o restaurante Sete Portes deve continuar a focar a sua atenção na qualidade de serviço, tendo em vista captar novos clientes e reter os já conquistados. No entanto, o restaurante Sete Portes deve também formalizar e estruturar um programa de fidelização, tendo por base a avaliação do valor atual e potencial dos clientes.

$O$ estudo de caso foca explicitamente o modelo de cooperação existente com organizações como a FICCG, Turismo de Barcelona e Turismo da Catalunha, relativamente ao restaurante Sete Portes. Por exemplo, é de destacar o auxílio prestado pelo Turismo de Barcelona e da Catalunha, quando a equipa de gestão do restaurante precisa de dados económicos ou quando o restaurante Sete Portes pretende ver o seu nome divulgado a nível nacional e internacional. Todavia, é de salientar que, poderiam ser criadas relações mais estreitas entre as instituições públicas governamentais que trabalham com a indústria do turismo e a restauração. Embora se verifique alguma entreajuda destas organizações, ainda pode haver, por exemplo, maior divulgação institucional.

A FICCG é outro órgão importante, na forma como tem contribuído para aumentar a notoriedade da cozinha e da Marca Cuina Catala, assim como dos restaurantes que consigo trabalham em parceria. Porém, é de destacar que esta marca deve incrementar ainda mais a sua colaboração com os restaurantes parceiros, no sentido de fomentar uma maior troca de 
impressões, participação conjunta em congressos internacionais e em feiras da especialidade gastronómica. Sugere-se ainda o desenvolvimento de um trabalho conjunto mais aprofundado, entre o Turismo de Barcelona e outras instituições, nomeadamente restaurantes pertencentes à Marca Cuina Catalana e a FICCG, para o desenvolvimento cultural e gastronómico da cidade de Barcelona.

Neste estudo de caso, observa-se uma especial importância dos clientes na concessão de referências positivas do restaurante Sete Portes. No entanto, não é totalmente claro o impacto do "passa-palavra" na mobilização de novos clientes para a empresa. Embora seja verdade que existem diversos públicos que chegam até ao restaurante Sete Portes, por intermédio das referências positivas que obtiveram de outras pessoas, cabe ao restaurante o poder de captar e fidelizar estes clientes, pois o bom "passa-palavra" está intimamente relacionado com a satisfação e com a capacidade da organização criar valor para os clientes. Ainda é de referir que o restaurante Sete Portes poderia criar, por exemplo, um cartão de recomendações. $O$ novo cliente poderia trazer um cartão de desconto que lhe fosse entregue por um cliente já fidelizado. O restaurante Sete Portes criaria assim um incentivo à concessão de referências dos atuais clientes junto dos seus amigos e familiares.

A direção do restaurante concede muita relevância a funcionários que trabalhem motivados e com sentido de responsabilidade. Mais ainda, procura recompensar monetariamente o esforço e o trabalho realizado pelos seus colaboradores. Todavia, ainda é importante ter em conta, outros sistemas de incentivos, para além do monetário, nomeadamente verificar se o colaborador se sente satisfeito com as tarefas que desenvolve no restaurante. Por outro lado, poderia ser realizado um encontro anual com todos os colaboradores, cujo principal objetivo fosse transmitir a análise dos resultados alcançados, reconhecer publicamente o mérito dos colaboradores e transmitir os objetivos a alcançar no futuro. Esta medida poderia ser importante, no sentido de motivar as pessoas e de fomentar o espírito de equipa.

Neste estudo de caso, verifica-se ainda que é dada importância ao recrutamento de funcionários, tendo estes de ser bem qualificados (com formação na área de turismo ou hotelaria) e comunicativos. No entanto, é importante definir de forma explícita e formal, o perfil de colaboradores que se desejam recrutar. Por outro lado, a adesão à rede social Linkedin, por exemplo, poderia ser uma mais-valia, uma vez que é uma das maiores plataformas on-line vocacionada para profissionais, podendo, com efeito, ser um eficiente canal de comunicação para o recrutamento de novos funcionários. Por fim, os colaboradores têm de estar altamente motivados (atendendo que a sua satisfação facilita o processo de recrutamento), porque a satisfação no trabalho é manifestada pelos colaboradores nos diferentes contextos sociais e, por conseguinte, é geradora de um clima de maior simpatia e confiança em relação ao restaurante.

O caso de estudo demonstra também que o restaurante Sete Portes estabelece relações de compra com alguns produtores locais. Contudo, deveria existir uma relação mais estreita com os fornecedores locais, no sentido de adaptarem-se de forma mais eficiente aos processos do restaurante e, deste modo, garantirem uma elevada qualidade nos fornecimentos, por exemplo, criando produtos ou serviços mais customizados e partilhando conhecimento junto dos funcionários. 
No que se refere às alianças estabelecidas, seria proveitoso estabelecer alianças entre o restaurante Sete Portes e os outros restaurantes pertencentes à Marca Cuina Catalana, na medida em que poderiam obter sinergias e "economias de escala". Por exemplo, através do desenvolvimento de campanhas de comunicação comuns e compras em grupo.

\section{Referências}

Aburoub, A., Hersh, A. \& Aladwan, K. (2011). Relationship between internal marketing and service quality with customers' satisfaction. International Journal of Marketing Studies, 3(2), 107-118. doi:10.5539/ijms.v3n2p107

Antunes, J. \& Rita, P. (2008). O marketing relacional como novo paradigma: Uma análise conceptual. Revista Portuguesa e Brasileira de Gestão, 7(2), 36-46.

Balta, S. (2018). The influence of internal marketing on employee satisfaction in the service industry. Business Management Dynamics, 8(1), 12-15.

Blunden, R. \& McGuinness, N. (1993). The real case method: A response to critics of business education. Case Research Journal, Winter, 106-119.

Brito, C. (2011a). Relationship marketing: Old wine in a new bottle? Innovative Marketing, 7(1), 66-77.

Brito, C. (2011b). Marketing relacional: Das origens às atuais escolas de Pensamento. Revista Portuguesa de Marketing, 26, 15-26.

Brito, C., Ramos, C. \& Carvalho, P. (2006). Parcerias no negócio eletrónico. Porto: Sociedade Portuguesa de Inovação.

Carvalho, P. (2004). O marketing relacional e o estudo de caso Chip 7 (Dissertação de mestrado não publicada), Universidade Portucalense, Porto.

Choi, E.-K. \& Joung, H.-W. (2017). Employee job satisfaction and customer-oriented behavior: A study of frontline employees in the foodservice industry. Journal of Human Resources in Hospitality \& Tourism, 16(3), 235-251. doi:10.1080/153328452.2017.1253428

Christopher, M., Payne, A. \& Ballantyne, D. (2002). Relationship marketing: Creating stakeholder value. Oxford: Butterworth-Heinemann.

Contreras, J. (2007). El património alimentario en la area mediterranea. In J. Tresserras \& F.X. Medina (Eds), Patrimonio gastronómico y turismo cultural en el Mediterráneo (pp. 17-37). Barcelona: Universidade de Barcelona (IBERTUR) e Instituto Europeu do Mediterrâneo.

Corey, R. (1996). The uses of cases in management education. Harvard Business School Publishing, September 23, 9-376-240.

Doh, J. P., Howton, S. D., Howton, S. W. \& Siegel, D. S. (2010). Does the market respond to an endorsement of social responsibility? The role institutions, information, and legitimacy. Journal of Management, 36(6), 480-485. doi:10.1177/0149206309337896

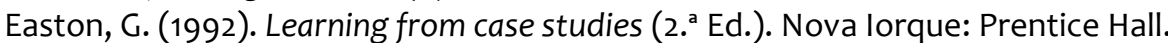

Estrella-Ramón, A., Sánchez-Pérez, M., Swinnen, G. \& Vanhoof, K. (2016). Estimating customer potential value using panel data of a Spanish bank. Journal of Business Economics and Management, 17(4), 580-597. doi:10.3846/16111699.2014.970571

Ford, D., Gadde, L., Hakansson, H., Lundgren, A., Snehota, I., Turnbull, P. \& Wilson, D. (1998). Managing Business Relationships. West Sussex, Inglaterra: John Wiley \& Sons.

Hyun, S. S. \& Perdue, R. R. (2017). Understanding the dimensions of customer relationships in the hotel and restaurant industries. International Journal of Hospitality Management, 64, 73-84.

Marques, A. (2012). Marketing relacional como transformar a fidelização de clientes numa vantagem competitiva. Lisboa: Edições Sílabo.

Peppers, D. \& Rogers, M. (1993). The one to one future: Building relationships one customer at a time. Nova Iorque: Currency/Doubleday.

Ryu, K. \& Lee, J.-S. (2017). Examination of restaurant quality, relationship benefits, and customer reciprocity from the perspective of relationship marketing investments. Journal of Hospitality \& Tourism Research, 41(1), 66 - 92. doi:10.1177/1096348013515919

Šonková, T. \& Grabowska, M. (2015). Customer engagement: Transactional vs. relationship marketing. Journal of International Studies, 8(1), $196-207$.

Tresserras, J. \& Medina, F.X. (2007) (Eds). Patrimonio gastronómico y turismo cultural en el mediterráneo. Barcelona: Universidade de Barcelona e Instituto Europeu do Mediterrâneo. 
World Travel \& Tourism Council (2016). Travel \& tourism. Economic impact 2016 - world. Londres: World Travel \& Tourism Council.

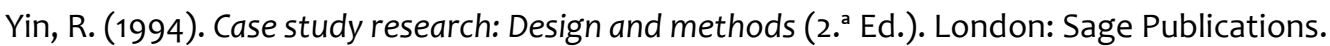

Yin, R. (2001). Estudo de caso: Planejamento e métodos (2. ${ }^{a}$ Ed.). (Trad. Daniel Grassi). Porto Alegre: Bookman.

ANA MÁRCIA PARENTE é licenciada em Arqueologia e História pela Universidade de Coimbra e mestre em Turismo, Inovação e Desenvolvimento pelo Instituto Politécnico de Viana do Castelo. Desempenhou funções na Câmara Municipal de Viana do Castelo como assistente de exposições e espetáculos promovidos pelo município, e foi assistente de gestão hoteleira e administrativa na Quinta da Cancela. Atualmente desempenha funções administrativas na sede da empresa Parfois. Endereço institucional: Instituto Politécnico de Viana do Castelo, Escola Superior de Tecnologia e Gestão, Avenida do Atlântico, n. ${ }^{\circ} 644,4900-348$ Viana do Castelo, Portugal.

PEDRO MIGUEL CARVALHO é doutorado em gestão de empresas na especialidade do marketing, pela Universidade da Extremadura (Espanha). É professor adjunto no Instituto Politécnico de Viana do Castelo, onde tem lecionado nas áreas do marketing e gestão a cursos de licenciatura e mestrado. Tem também desenvolvido investigação em marketing turístico no Centro de Investigação, Desenvolvimento e Inovação em Turismo (CITUR). Para além da atividade académica e de investigação, foi empresário e vencedor do Prémio do Empreendedor, na categoria da Inovação da Associação Nacional de Jovens Empresários. Endereço institucional: Instituto Politécnico de Viana do Castelo, Escola Superior de Tecnologia e Gestão, Avenida do Atlântico, n. ${ }^{\circ} 644$, 4900-348 Viana do Castelo, Portugal.

Submetido em 21 agosto 2018

Aceite em 28 fevereiro 2019 